\title{
NGHIÊN CỨU ĐĂC ĐIỂM TỔN THƯƠNG VÕNG MAC MẮT CỦA BÊNH NHÂN ĐÁI THÁO ĐƯờNG TÍP 2 BẰNG MÁY CHỤP VõNG MẠC KỸ THUẬT Số DRS
}

\begin{abstract}
Đỗ Đìn
TÓM TẮT

Bệnh đái tháo đường gây ra nhiều biến chứng nguy hiểm trong đó có biến chứng về mắt, đặc biệt là bệnh lý võng mạc có thể dẫn đến mù lòa nên cần phải nghiên cứu để có kế hoạch sàng lọc, can thiệp, điều trị sớm. Nghiên cứu bệnh lý mắt cưa 145 người đái tháo đường, tuổi trung bình $60,88 \pm 8,11$ cho thây: Tỉ lệ bệnh nhân có đục thủy tinh thể chiếm tỉ lệ cao $42,7 \%$. Tỷ lệ các tổn thương võng mạc gân tương đương nhau giữa mắt phải và mắt trái. Tỷ lệ bệnh nhân có vi phình mach, xuất tiết cứng, xuất huyết mềm chiếm tỉ lệ cao hơn so với các tổn thương khác. Tỷ lệ bệnh mắt chưa tăng sinh mức độ vừa chiếm tỉ lệ cao nhất $66,1 \%$, vẫn còn tới $22,6 \%$ thể nặng và rất nặng. Bệnh mắt chủ yếu ở người đái tháo đường là đục thủ tinh thể, bệnh lý kết mạc, bệnh lý giác mạc. Tổn thương võng mạc do đái tháo đường ở 2 mắt là tương đương nhau; trong đó chủ yếu là bệnh VMĐTĐ chưa tăng sinh vừa và nhe chiếm tỉ lệ rất cào.
\end{abstract}

Tư khóa: Đái tháo đường; biến chứng; Bệnh lý võng mạc mắt

\section{SUMMARY}

INVESTIGATING CHARACTERISTICS OF REIINOPATHY USING DIGITAL RETINOGRAPHY SYSTEM AMONG DIABETES IN VIETNAM

Diabetes causes many dangerous complications, including eye complications, especially retinopathy that can lead to blindness, so it is necessary to study to plan screening, intervention, and early treatment. Research on eye pathology of 145 people with diabetes, average age $60.88 \pm 8.11$ shows that: The rate of patients with cataracts accounts for a high rate of $42.7 \%$. The rate of retinal lesions was approximately equal between the right and left eyes. The proportion of patients with microaneurysms, hard exudates, soft bleeding accounts for a higher rate than other lesions. The rate of eye disease not yet proliferating moderate level accounted for the highest rate of $66.1 \%$, still up to $22.6 \%$ with severe and very severe form. The main eye diseases in people with diabetes are cataracts, conjunctivitis, and corneal diseases. Diabetic retinal damage in both eyes is similar; in which, the proportion of moderate and mild non-proliferative DR is mainly.

Keywords; Diabetes; complications; retinopathy

\footnotetext{
${ }^{1}$ Hoc viện Quân $Y$

²Bênh viên Đa Khoa Xanh Pôn

${ }^{3}$ Tạp chí Đái tháo đường

Chịu trách nhiệm chính: Đỗ Đình Tùng

Email: bsdinhtung@gmail.com

Ngày nhận bài: 25.10.2021

Ngày phản biện khoa học: 20.12.2021

Ngày duyệt bài: 27.12.2021
}

I. ĐặT VẤN ĐỀ

Bệnh đái tháo đường gây ra nhiều biến chứng nguy hiểm: bao gồm các biến chứng cấp tính và biến chứng mạn tính. Biến chứng mạn tính thường gặp là các bệnh về tim mạch, bệnh thận, về thần kinh và bệnh về mắt,...

Bệnh võng mạc đái tháo đường (VMĐTĐ) là biến chứng hay gặp nhất trong bệnh lý mắt do đái tháo đường. Ước tính rằng và̀o năm 2040, 642 triệu người sẽ mắc đái tháo đường, 35\% (224 triệu) trong số đó sẽ có bệnh VMĐTĐ, và $11 \%$ (70 triệu) có nguy cơ mù lòa.

Ở Việt Nam, bệnh ĐTÐ và bệnh VMĐTÐ ngày càng gia tăng. Hiển nay, các nghiên cứu về đăc điểm bệnh VMĐTĐ̇ còn hạn chế đặc biệt là các nghiên cứu có sử dụng máy chụp võng mạc kỹ thuật số DRS. Mục tiêu:

1. Mô tả đặc điểm, tỉ lệ tổn thương mắt ở bệnh nhân đái tháo đường típ 2 tại bệnh viện tinh Thái Binh.

2 Xác định tỉ lệ các tổn thương bệnh lý võng mạc mắt đái tháo đường máy chụp đáy mắt kỹ thuật số DRS.

\section{II. ĐỐI TƯƠNG VÀ PHƯƠ'NG PHÁP NGHIÊN CỨU}

- Đối tượng nghiên cứu: Nghiên cứu được tiến hành trên 145 bệnh nhân đái tháo đường típ 2 đang điều trị ngoại trú tại Bệnh viện Đa khoa Tỉnh Thái Bình từ tháng 6/2020 đến tháng 7/2021.

+ Tiêu chuẩn lựa chọn: Những bệnh nhân $\geq 40$ tuổi được chẩn đoán xác định ĐTĐ típ 2 đang được điều trị ngoại trú tại Bệnh viện Đa khoa Tỉnh Thái Bình và đồng ý tham gia nghiên cứu.

+ Tiêu chuẩn loại trừ: Không đồng ý tham gia nghiên cứu; ĐTÐ típ 1; ĐTÐ thai kỳ; đang mắc bệnh cấp tính; bệnh nhân không soi rõ đáy mắt do có mộng thịt độ 3 , sẹo trung tâm giác mạc, đục thể thủy tinh, vẩn đục dịch kính nặng.

- Phương pháp nghiên cứu mô ta cắt ngang kết hợp với phân tích.

- Phương tiện nghiên cứu: Bảng thị lực Landolt; Hộp thử kính; Nhãn áp kế Goldmann; Sinh hiển vi khám bệnh; Đèn soi đáy mắt trực tiếp, gián tiếp; Kính Volk + 20D, + 90D; Máy chụp đáy mắt không giãn đồng tử (DRS).

- Các tiêu chuẩn đánh giá sử dụng trong nghiêu cứu: Chẩn đoán tiền ĐTĐ theo WHO-IDF năm 2010; đánh giá chỉ số khối cơ thể (BMI), 
vòng eo theo tiêu chuẩn của WHO 2000 áp dụng cho người trưởng thành Châu Á; Phân độ tăng huyết áp theo Hội Tim Mạch Việt Nam 2018; Tiêu chuẩn chẩn đoán bệnh VMĐTĐ (Alphediam).
- Địa điểm nghiên cứu: Tại tỉnh Thái Bình

- Quản lý và xử lí số liệu bằng phân mềm Epidata và SPSS 15.0.

\section{KẾT QUẢ NGHIÊN CỨU}

\section{1. Đăc điểm chung của đối tượng nghiên cứu}

Bảng 1. Đăc điểm phân bồ tuổi và bênh kèm theo của nhóm nghiên cứu

\begin{tabular}{|c|c|c|c|c|c|}
\hline Tuối & $\mathbf{n}$ & $\mathbf{\%}$ & Tiền sử & $\mathbf{n}$ & $\mathbf{\%}$ \\
\hline$<50$ & 12 & 8,3 & THA & 60 & 41,4 \\
\hline $50-60$ & 49 & 33,8 & Bệnh lý TM & 8 & 5,5 \\
\hline $61-70$ & 68 & 46,9 & RLLM & 30 & 20,7 \\
\hline$>70$ & 16 & 11,0 & Bệnh lý thận & 17 & 11,7 \\
\hline $\mathbf{X} \pm$ SD (năm) & $60,88 \pm 8,11$ & Bệnh lý khác & 25 & 17,2 \\
\hline
\end{tabular}

Nhân xét: Nhóm tuối từ 50-70 tuối chiếm tỷ lệ cao nhất với 80,7\%; bệnh nhân có tiền sử THA chiếm tỷ lệ cao nhất là 41,4\%.

Bảng 2. Đặc điểm tình trạng quản lý đường máu theo chỉ số HbA1c

\begin{tabular}{|c|c|c|}
\hline HbA1c(\%) & $\mathbf{n}$ & \% \\
\hline$<6,5$ & $14(6,26 \pm 0,27)$ & 10,2 \\
\hline $6,5-7,5$ & $49(7,06 \pm 0,28)$ & 35,8 \\
\hline$>7,5$ & $74(9,27 \pm 1,37)$ & 54,0 \\
\hline Tống (文 \pm SD) & $137(8,15 \pm 1,61)$ & 100 \\
\hline
\end{tabular}

Nhận xét: Tỉ lệ bệnh nhân kiếm soát HbA1c kém chiếm tỷ lệ còn rất cao trên $50 \%$.

2. Đặc điểm các tổn thương mắt của đối tượng nghiên cứu

Bảng 3. Đăc điểm mức độ thì lức của đôi tượng nghiên cứu

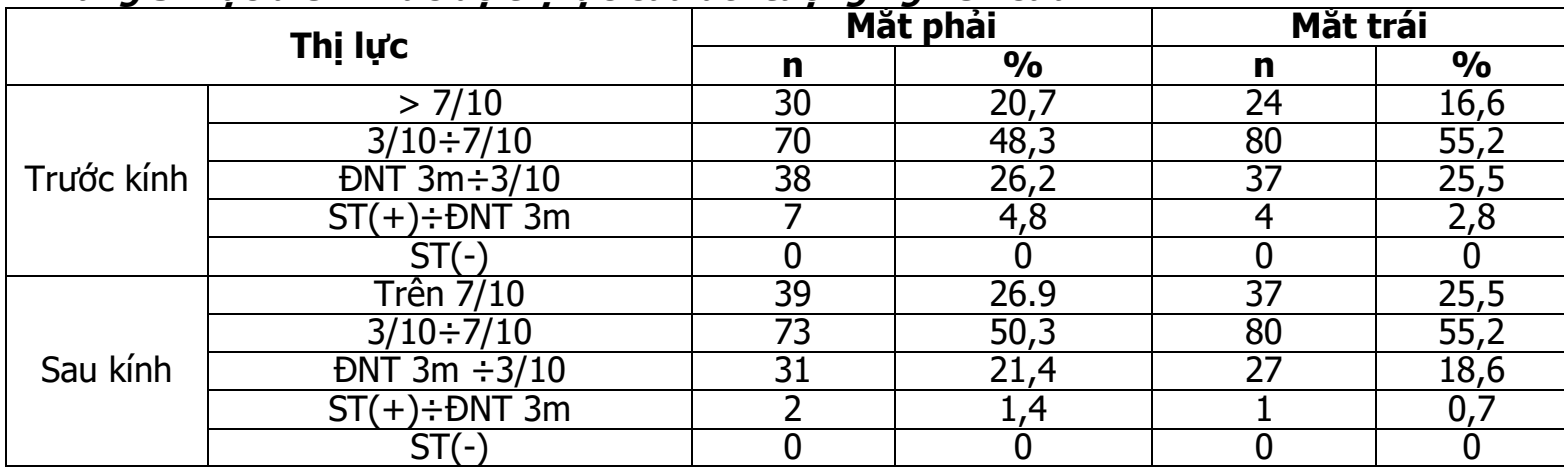

Nhân xét: Thi lực mắt phải trước kính có $26,2 \%$ bệnh nhân có thị lực thấp và $4,8 \%$ gân mù, Mắt trái $25,5 \%$ có thị lực thấp và $2,8 \%$ gân mù. Thị lực sau kính mắt phải $21,1 \%$ thị lực kém và $1,4 \%$ gân mù; mắt trái $18,6 \%$ thị lực kém và $0,7 \%$ gần mù.

Bảng 4. Tỉ lệ các bệnh lý mắt kèm theo của bệnh nhân

\begin{tabular}{|c|c|c|}
\hline Bệnh lý & $\mathbf{n}$ & $\mathbf{\%}$ \\
\hline Đục thủy tinh thế & 61 & 42,7 \\
\hline Tăng nhãn áp & 1 & 0,7 \\
\hline Bệnh lý kết mạc & 14 & 9,7 \\
\hline Bệnh lý giác mạc & 9 & 6,2 \\
\hline
\end{tabular}

Nhân xét; Tỉ lệ có đục thủy tinh thế kèm

3. Đặc điểm, tỉ lệ các tổn thương bệnh lý võng mạc mắt

Bảng 5. Tỉ lế tình trạng các tổn thương bệnh lý vỗng mạc mắt

\begin{tabular}{|c|c|c|c|c|}
\hline \multirow{2}{*}{ Bệnh lý } & \multicolumn{2}{|c|}{ Mắt phải } & \multicolumn{2}{c|}{ Mắt trái } \\
\cline { 2 - 5 } & $\mathbf{n}$ & $\mathbf{\%}$ & $\mathbf{n}$ & $\mathbf{\%}$ \\
\hline Vi phình mạch & 21 & 14,5 & 21 & 14,5 \\
\hline MM võng mạc thay đối & 4 & 2,8 & 3 & 2,1 \\
\hline Xuất huyết dịch kính & 4 & 2,8 & 1 & 0,7 \\
\hline Xuất huyết võ̃ng mạc & 11 & 7,6 & 12 & 8,3 \\
\hline Xuất tiết cứng & 38 & 26,2 & 45 & 31 \\
\hline Xuất huyết mềm & 19 & 13,1 & 16 & 11 \\
\hline
\end{tabular}


VIETNAM MEDICAL JOURNAL N01 - JANUARY - 2022

\begin{tabular}{|c|c|c|c|c|}
\hline Phù hoàng điểm & 6 & 4,1 & 4 & 2,8 \\
\hline Tân mạch võng mạc & 2 & 1,4 & 1 & 0,7 \\
\hline
\end{tabular}

Nhận xét: Tỷ lệ các tổn thương võng mạc gần tương đương nhau giữa mắt phải và mắt trái. Tỷ lệ bệnh nhân có vi phình mạch, xuất tiết cứng, xuất huyết mềm chiếm tỉ lệ cao hớn so với các tổn thương khác

Bảng 7. Đăc điểm bênh lý vông mạc tăng sinh và chưa tăng sinh

\begin{tabular}{|c|c|c|c|}
\hline \multicolumn{2}{|c|}{ Tình trạng tốn thương } & $\mathbf{n}$ & $\mathbf{0}$ \\
\hline \multirow{4}{*}{$\begin{array}{c}\text { Chưa tăng } \\
\text { sinh }\end{array}$} & Nhẹ & 5 & 8,1 \\
\cline { 2 - 4 } & Vừa & 41 & 66,1 \\
\cline { 2 - 4 } & Nặng & 9 & 14,5 \\
\cline { 2 - 4 } & Rất nặng & 5 & 8,1 \\
\hline \multicolumn{2}{|r|}{ Tăng sinh } & 3 & 3,2 \\
\hline
\end{tabular}

Nhận xét: Có 62 bệnh nhân có tổn thương võng mạc đái tháo đường với đầy đủ các mức độ tổn thướng chưa tăng sinh. Tỷ lệ mắt chưa tăng sinh mức độ vừa chiếm tỉ lệ cao nhất $66,1 \%$.

\section{BÀN LUÂN}

1. Đặc điểm chung của đối tượng nghiên cứu. Nghiên cứu bệnh mắt 145 bệnh nhân ĐTĐ tại Bệnh viện Đa khoa tỉnh Thái Bình, có độ tuổi trung bình $60,88 \pm 8,11$ tuổi (nhỏ nhất 40, lớn nhất 84 tuổi), nhóm có độ tuổi từ $50-70$ chiếm 80,7\%. Theo Lê Thị Hiền (2020) Nguyễn Trong Khải (2018) đây là độ tuổi thường mắc bểnh VMĐTĐ. Kết quả có $41,4 \%$ bệnh nhân có tăng huyết áp. Một số nghiên cứu khác lại cho thấy tỷ lệ bệnh nhân có tăng huyết áp chiếm trên $50 \%$ như nghiên cứu của Nguyễn Trọng Khải, của Nguyễn Diệu Linh.

Tỷ lệ tăng trigricerid máu 40,8\%, tỷ lệ có tăng LDL máu đạt $14 \%$. Tỷ lệ này tương đương với tỷ lệ tăng mỡ máu 32,9\% ở nghiên cứu tại Thái Nguyên của Nguyễn Hương Thanh (2010), trong khi đó, nghiên cứu của Nguyễn Trọng.

Chỉ có $44,5 \%$ bệnh nhân ĐTĐ có kết quả trung bình và tốt. Kết quả này thấp hơn nhiều so với nghiên cứu của Nguyễn Trọng Khải (2018) với tỷ lệ $83,8 \%$. Nhưng cao hơn so với nghiên cứu của Nguyễn Hương Thanh (2010) và Nguyễn Kim Lương (2011) với tỷ lệ lần lượt là 53\% và 70\%

2. Đặc điểm các tổn thương mắt của đối tượng nghiên cứu. Trong nghiên cứu này chúng tôi thây có đầy đủ các hình thái biến chứng mắt do bệnh đái tháo đường: có 62 bệnh nhân có ít nhất tổn thương ở một hoặc hai mắt. So sánh biến chứng tổn thương đáy mắt với các biến chứng mắt khác, tỷ lệ bệnh nhân có tổn thương đáy mắt cao hơn so với nghiên cứu của Kawashima (2011) (10,5\%); Nguyễn Thị Thu Thủy (2009) 28,7\%. Trong khi các tổn thương như đục thể thủy tinh cũng gặp với tỷ lệ rất cao với $42,7 \%$, bệnh tăng nhãn áp có tỷ lệ thấp hơn chỉ $0,7 \%$. Các số liệu này cao hơn nhiều so với kết quả nghiên cứu của Orcutt $(8,6 \%$ đục thể thủy tinh) và tương đương với nghiên cứu tại Thái Nguyên của Nguyễn Hương Thanh (37,3\% đục thủy tinh thể). Việc phát hiện sớm các biến chứng này đóng vai trò quan trọng như việc phát hiện sớm bệnh.

Phần lớn các đối tượng đều có sự suy giảm về thị lực, tỷ lệ bênh nhân có thị lực 7/10 trở lên chỉ có $20,7 \%$. Tỷ lệ này tương đướng với nghiên cứu của Nguyễn Trọng Khải với $20 \%$ số bệnh nhân có thị lực trên $7 / 10$, nhưng thấp hơn nghiên cứu của Nguyễn Hương Thanh $(54,6 \%)$. Tỷ lê mắt có thị lực ĐNT < $3 \mathrm{~m}$ là 1,4\%, Trong nghiên cứu của Yamamoto có $1,6 \%$ bệnh nhân có thị lực St $(-)$, nghiên cứu của Arun (0,56\%) tại Anh.

3. Đặc điểm, tỉ lế các tổn thương bệnh lý võng mạc mắt. Tỷ lệ bệnh nhân có xuất tiết mềm ở mắt trong nghiển cứu là $13,1 \%$ ở mắt phải và $11 \%$ ở mắt trái. Tỷ lệ này tương đương so với nghiên cứu của Nguyễn Trong Khải, nhưng thấp hơn nghiên cứu năm 2004 tại Los Angeles (21,8\%).

Các tổn thương khác trên mắt ở đối tượng nghiên cứu như phù hoàng điểm, mạch máu võng mạc thay đổi, xuất huyết dịch kính chỉ chiếm tỉ lệ nhỏ (dưới $5 \%$ ) và đều thấp hơn kết quả nghiên cứu tại Los Angeles của Varma (trên $6,5 \%)$, tuy nhiên tỷ lệ các tổn thương như xuất huyết võng mạc, vi phình mạch chiến tỷ lệ tương đối cao với $14,5 \%$ có vi phình mạch, $8,3 \%$ có xuất huyết võng mạc, tỷ lệ bệnh nhân có tổn thương xuất tiết cứng lần lượt $26,2 \%$ trên mắt phải và $31 \%$ trên mắt trái, tương đương với kết quả nghiên cứu tại Bệnh viện Đại học Y - Dược Thành phố Hồ Chí Minh cho thấy tỉ lệ biến chứng tại mắt chung là $54,7 \%$, trong đó, đục thể thủy tinh 38,5\%, bệnh VMĐTĐ $28,7 \%$, phù hoàng điểm 3,3\%. Riêng với bệnh VMĐTĐ, bệnh VMĐTĐ không tăng sinh mức nhe chiếm 14,5\%, mức trung bình là $58,1 \%$, nặng là $19,4 \%$ và bệnh VMĐTĐ tăng sinh chiếm 4,8\%. Kết quả nghiên cứu của chúng tôi có số liệu cũng tương đương với nghiên cứu ở Bệnh viện Đại học YDược Thành phố Hồ Chí Minh do triển khai trên đối tượng là các bệnh nhân đang nằm viện, hâu hết các đối tượng này có các triệu chứng, biến chứng nặng hơn so với các nghiên cứu trên trên cộng đồng. Các tổn thương này gây tác động 
đến chức năng của mắt, nên việc kiểm soát các tổn thương taii mắt rất quan trọng, cần thiết để đánh giá, phát hiện, quản lý bệnh võng mạc đái tháo đường.

Đánh giá chung về tổn thương võng mạc do ĐTÐ cho thấy tỷ lệ bệnh nhân có tổn thương tới $42,8 \%$. So sánh với kết quả nghiên cứu của Orcutt tại Mỹ $(13,9 \%)$, tỷ lệ của chúng tôi cao hơn. Điều này cũng dế hiểu do Mỹ là nước phát triển, điều kiện kinh tế và chăm sóc y tế cao hơn hẳn Việt Nam. Nghiên cứu của Xu (2012) cho thấy tỷ lệ 24,7\% mắc bệnh VMĐTĐ ở người Bắc Kinh. Mặt khác, trong các bệnh nhân mắc bệnh VMĐTĐ, phần lớn còn ở tình trạng tổn thương võng mạc chưa tăng sinh mức độ nhe và vừa (trên $74,2 \%$ ). Tuy nhiên, có $66,1 \%$ bệnh nhân có tình trạng chưa tăng sinh mức độ vừa. Đặc biệt, vẫn có các trường hợp có tăng sinh mức độ nặng rất nặng chiếm $3,2 \%$ số bệnh nhân có tình trạng tổn thương VM tăng sinh. Đây là tình trạng khá nghiêm trọng tổn thương võng mạc, đòi hỏi các biện pháp điều trị chặt chẽ.

Do tình trạng phổ biển của tổn thương võng mạc nên đặt ra yêu cầu sàng lọc sớm nhằm duy trì và giảm thiểu tình trạng tổn thương võng mạc của các bệnh nhân ĐTÐ, đồng thời ngăn ngừa những biến chứng mà bệnh nhân có thể gặp phải, tránh các ảnh hưởng đáng tiếc tới thị lực.

\section{KẾT LUẬN}

1. Bệnh mắt chủ yếu ở người đái tháo đường là đục thủ tinh thể, bệnh lý kết mạc, bệnh lý giác mạc, bệnh lý võng mạc.

2. Tổn thương võng mạc do đái tháo đường tương đương ở 2 mắt; trong đó chủ yếu là bệnh VMĐTĐ chưa tăng sinh thể vừa và nhe chiếm $74,2 \%$, có $22,6 \%$ thể nặng và rất nặng.

\section{TÀI LIÊU THAM KHẢO}

1. Ta Văn Bình (2006). Bệnh đái tháo đường - Tăng glúcose máu. Nhà xuât bản Y học, Hà Nội, 45-76.

2. W. H. Organization.( 2020), "Strengthening diagnosis and treatment of Diabetic Retinopathy in SEA Region,".

3. R. Lee, T. Y. Wong, and C. Sabanayagam.( 2015), "Epidemiology of diabetic retinopathy, diabetic macular edema and related vision loss," (in eng), Eye Vis (Lond), vol. 2, p. 17.

4. M. V.' Van Hecke et al.( 2005), "Diabetic retinopathy is associated with mortality and cardiovascular disease incidence: the EURODIAB prospective complications study," vol. 28, no. 6, pp. 1383-1389.

5. J. W. Yau et al.( 2012), "Global prevalence and major risk factors of diabetic retinopathy," vol. 35, no. 3, pp. 556-564.

6. N. T. T. Thủy, T. A. Tuấn, and D. T. Bình.( 2009), "Khảo sát biến chứng tai mắt trên bênh nhân đái tháo đường điều trị tại Bệnh viện Đại học y dược TP. Hồ Chí Minh," Tạp chí Ỳ học TP. Hồ Chí Minh, vol. 13, pp. 86 - 91.

7. P. V. Priya, A. Srinivasarao, and J. J. I. J. S. I. T. Sharma.(2013), "Diabetic Retinopathy-Can Lead To Complete Blindness," vol. 2, no. 4, pp. 254-265.

8. H. A. Kahn and R. J. A. j. o. o. Hiller.(1974), "Blindness caused by diabetic retinopathy," vol. 78, no. 1 , pp. 58-67.

\section{MỐI LIÊN QUAN GIỮA SỨC KHOẺ RĂNG MIÊNG VớI CHẤT LƯợNG CUộC SỐNG Ở NGƯỜI CAO TUỔI TİNH BÌNH DƯƠNG}

\section{TÓM TẮT}

Mục tiêu nghiên cứu nhằm tìm hiểu mối liên quan giữa bệnh sâu răng, viêm quanh và tình trạng mất răng với chất lượng cuộc sống ở người cao tuối (NCT) ở tình Bình Dương. Đối tượng nghiên cứu là người cao tuổi (> 60 tuổi) của tỉnh Bình Dương. Phương pháp nghiên cứu: mô tả cắt ngang thực hiện trến 1350 NCT. Kết quả cho thây điểm OHIP

\footnotetext{
${ }^{1}$ Bệnh viện Răng Hàm Mặt Trung Uơng Hà Nội 2Phòng khám nha khoa thẩm mỹ Phương Đông 3 Viện DT Răng Hàm Mặt, Trướng Đại Học Y Hà Nội Chịu trách nhiệm chính: Võ Thị Thuý Hồng Email: vothuyhong71@yahoo.com Ngày nhận bài: 22.10.2021 Ngày phản biện khoa học: 21.12.2021 Ngày duyệt bài: 29.12.2021
}

14VN nhóm mất răng: 7,64 điểm (so với nhóm mất răng: 6,92 điểm); OR: 2,42 (CI 95\%: 1,29 - 4,56). Điểm OHIP 14VN nhóm NCT bi VQR là 8,15 điểm (so với nhóm không bị VQR 7,35 điểm); OR 1,52 (CI 95\%: $1,1-2,1)$. Điển OHIP 14VN nhóm có dưới 3 VLPLM là 7,82 điểm (so với 5,28 điểm); OR 2,62 (CI 95\% 1,31$5,24)$. Kết luân: Bệnh sâu rằng, viêm quanh răng và tình trạng mất răng gây ảnh hưởng tới chất lượng cuộc sổng của người cao tuổi tỉnh Bình Dương.

Tư khoá: sẩu răng, viêm quanh răng, mất răng, chất lượng cuộc sống.

\section{SUMMARY \\ ASSOCIATION OF ORAL HEALTH AND LIFE QUALITY OF ELDERLY PEOPLE IN BINH DUONG PROVINCE}

Abstract: The objective of the study was to find out the associations between caries, periodontitis and 